\title{
Idosos brasileiros: o contexto dos direitos sociais e das políticas sociais
}

\author{
Brazilian elderly: the context of social rights and social political

\section{Rosilaine Brasil KUNZLER ${ }^{1}$ Leonia Capaverde BULLA ${ }^{2}$}

\begin{abstract}
Resumo: Este artigo trata da situação social do idoso no Brasil, no qual tecemos breves considerações no campo das políticas e dos direitos sociais em um país que gradativamente envelhece, como é o caso do Brasil, considerando-se que a expectativa média de vida do brasileiro aumentou para 74 anos e 29 dias (74,08 anos), no ano de 2012, de acordo com os dados do Instituto Brasileiro de Geografia e Estatística (IBGE). O número representa um acréscimo de três meses e 22 dias em relação a 2010 (73,76 anos) e de 3,65 anos ( 3 anos, 7 meses e 24 dias) sobre o indicador de 2000. Se antes a velhice era predominantemente feminina, agora essa característica também se altera, pois esse ganho na expectativa de vida dos brasileiros na última década foi maior para os homens: 3,8 anos contra 3,4 anos para mulheres, correspondendo a um acréscimo de 5 meses e 23 dias. As novas concepções e características próprias das fases da aposentadoria e da velhice são cada vez mais atingíveis para homens e mulheres. As implicações desta nova realidade clamam pela urgente formulação de políticas sociais e programas adequados, voltados a este segmento específico da população, os quais não evoluem com a mesma velocidade que a população que envelhece. É preciso viabilizar o acesso às políticas sociais como direitos dos cidadãos, conquistados ao longo de todo o processo de envelhecimento, para que ao chegar à velhice, ela não seja desamparada e segregada da sociedade.
\end{abstract}

Palavras-chave: Idosos. Políticas Sociais. Direitos Sociais. Proteção Social.

\begin{abstract}
This article deals with the social situation of the elderly in Brazil, where we weave brief considerations in the field of political and social rights in a country that gradually grows older, as is the case in Brazil, considering that the average life expectancy in Brazil has increased to 74 years and 29 days (74.08 years), in the year 2012, according to data from the Brazilian Institute of Geography and Statistics (IBGE). The number represents an increase of three months and 22 days compared to 2010 (73.76 years) and 3.65 years ( 3 years, 7 months and 24 days) on the indicator before 2000 If old age was predominantly female now this feature is also altered, since this gain in life expectancy of Brazilians in the last decade was greater among men: 3.8 years against 3.4 years for women, corresponding to an increase of 5 months and 23 days. The new concepts and characteristics of the phases of retirement and old age are increasingly attainable for men and women. The implications of this new reality call for the urgent development of adequate social policies and programs aimed at this specific segment of the population, which does not evolve at the same speed that the aging population. You need to enable access to social policies and rights of citizens, conquered throughout the aging process, so to reach old age, she is not helpless and segregated society.
\end{abstract}

Keywords: Seniors. Social Policies. Social Rights. Social Protection.

Submetido em 28/04/2014. Aprovado em 13/07/2014.

\begin{abstract}
${ }^{1}$ Assistente Social (PUCRS, Brasil). Doutora em Serviço Social da Pontifícia Universidade Católica do Rio Grande do Sul (PUCRS, Brasil). Assistente Social no Exército Brasileiro (2006 a 2014). Pós-Doutoranda em Serviço Social (PNPD/CAPES) pelo Programa de Pós-Graduação em Serviço Social da PUCRS. Membro da Equipe de Pesquisadores do Núcleo de Pesquisas em Demandas e Políticas Sociais (NEDEPS). E-mail: < rosekunzler@bol.com.br>.

${ }^{2}$ Assistente Social (UFSC, Brasil). Doutora em Ciências Humanas: Educação, Faculdade de Educação da Universidade Federal do Rio Grande do Sul (UFRGS, Brasil). Pós-Doutorado em Serviço Social (Universidade de Kassel, Alemanha). Professora da Faculdade de Serviço Social da Universidade Católica do Rio Grande do Sul (PUCRS, Brasil). Coordenadora do Núcleo de Pesquisas em Demandas e Políticas Sociais e do Grupo de Pesquisa em Gerontologia Social da PUCRS (Brasil). Pesquisadora nível 1B do Conselho Nacional de Desenvolvimento Científico e Tecnológico do Brasil. Membro do Comitê Interdisciplinar da Fundação de Amparo à Pesquisa do Rio Grande do Sul (Brasil). E-mail:<lbulla@pucrs.br > .
\end{abstract}

Argumentum, Vitória (ES), v. 6, n.1, p. 153-159, jan.jun. 2014. 


\section{Introdução}

sociedade contemporânea é tes-

$\mathrm{A}$ temunha de transformações históricas, políticas, sociais e culturais. O avanço tecnológico e os progressos científicos que marcaram a história da humanidade no século XXI têm garantido a longevidade. $\mathrm{O}$ momento atual é pleno de transformações, na condição da realidade demográfica do país, pois a tendência ao envelhecimento da população brasileira cristalizou-se mais uma vez na nova pesquisa do IBGE (Instituto Brasileiro de Geografia e Estatística). Os idosos brasileiros somam atualmente 23,5 milhões de pessoas. Isso representa mais que o dobro do registrado em 1991, quando contabilizava 10,7 milhões de pessoas. Na comparação entre 2009 e 2011 (última pesquisa divulgada), o grupo de idosos aumentou 7,6\%, ou seja, mais 1,8 milhões. Há dois anos, eram 21,7 milhões de pessoas (IBGE, Pesquisa Nacional de Amostra por Domicílio, 2012).

É importante ressaltar que a população de idosos está crescendo mais rapidamente que a de crianças, pois os mesmos dados afirmam que o número de crianças de até quatro anos no país caiu de 16,3 milhões, em 2000, para 13,3 milhões, em 2011 (IBGE, Pesquisa Nacional de Amostra por Domicílio, 2012). Se analisarmos a década de 1980, constata-se que existiam 16 idosos para cada 100 crianças. No ano de 2000, essa característica aumentou para 30 idosos por criança, demonstrando o dobro em 20 anos. Para entendermos essas mudanças, é preciso considerarmos fatores como planejamento familiar, que- da da taxa de fecundidade e aumento da longevidade.

Nesse sentido, há de se considerar que as conquistas que se vislumbravam para o futuro, já estão acontecendo no presente, pois à medida que o tempo e a ciência avançam, a longevidade é a perspectiva de um número cada vez maior de pessoas, em nível mundial. Essa nova realidade demográfica, impõe à humanidade rever o momento de chegada da aposentadoria, os direitos sociais e as políticas públicas direcionadas a essa parcela da população.

\section{Os direitos sociais dos idosos no Brasil}

A Constituição Federal (BRASIL, 1988) veio firmar uma nova era na trajetória histórica no campo dos direitos sociais no país. No contexto político e econômico, a saúde, a previdência e a assistência social são homologadas como políticas sociais públicas, compondo os três pilares da Seguridade Social Brasileira. Alicerçada em princípios de liberdade, equidade e universalidade, o acesso a cada uma das políticas que compõem o sistema previdenciário público requer ser considerado na ótica do direito do cidadão e dever do Estado. Nesse sentido, a Constituição Federal define a Seguridade Social enquanto um "conjunto de políticas e ações que visam à proteção do cidadão e de seu grupo familiar, quando da materialização das situações de risco de saúde, perda da capacidade laborativa e/ou necessidades econômica" (BRASIL, 1988).

Os idosos podem ter assegurados os seus direitos formalmente, pelo Estatuto do Idoso, Lei 10.741, de $1^{\mathrm{o}}$ de outubro de 2003 (BRASIL, 2003), data considerada o 
“Dia Internacional do Idoso". Até ser sancionado pelo Congresso Nacional, o Estatuto do Idoso percorreu uma longa trajetória. Os princípios que deram origem a essa lei foram democraticamente discutidos em debates, encontros e seminários, tendo como sujeitos os dirigentes de entidades representativas de aposentados, pensionistas e idosos de várias localidades do Brasil. Sem dúvida, a aprovação do Estatuto do Idoso pelo Congresso Nacional representou um marco histórico na legitimação de uma velhice digna aos brasileiros. A efetivação e usufruto dos direitos em defesa do idoso, entretanto, não estão sendo cumpridos em sua integralidade ainda que em vigor, ou seja, as leis por si só, se implementadas e não fiscalizadas, não garantem a cidadania e a autonomia plena daqueles a quem se destinam.

Em alguns países como a França, a Espanha e Alemanha, os idosos são reconhecidos e respeitados em seus direitos, tendo a seu dispor todo o amparo de uma rede interinstitucional. No Brasil, o desligamento do mercado de trabalho em torno dos 60 anos para as mulheres e 65 anos para os homens, os ínfimos valores das aposentadorias e o descaso aos idosos, na fase posterior ao ingresso na condição de aposentados, são fatores que contribuem para prejudicar as condições de vida na velhice.

As possibilidades de acesso à saúde, assistência, educação, habitação e seguridade social e todas as demais medidas de proteção aos idosos, que são prescritas pelo Estatuto do Idoso, representam uma mudança de cultura, na concepção, na maneira de pensar e viver a velhice numa sociedade que sempre teve uma imagem depreciativa das pessoas mais velhas, associando o idoso a um verdadeiro fardo para a família e para o erário.

A Constituição Federal de 1988 reconheceu o idoso como segmento especial da população, conforme prevê em seu Art. 230 que diz: "a família, a sociedade e o Estado têm o dever de amparar as pessoas idosas, assegurando sua participação na comunidade, defendendo sua dignidade e bem-estar, garantindo-lhes direito à vida" (BRASIL, 1988). É dever de toda a sociedade, portanto, criar alternativas para que o idoso tenha condições dignas de vida, embora se defronte com as ideias daqueles que privilegiam os que produzem, não os idosos, que, em sua maioria, são aposentados e pensionistas do Sistema Previdenciário do País.

Por interesses convencionais, a sociedade concentra sua atenção e seus serviços na juventude e seus valores, sendo, portanto, a velhice discriminada, pois é constituída por aqueles que já passaram da fase de produção econômica. Nesse cenário, o conhecimento e o trabalho passaram a ser um meio de pertencimento social e a aposentadoria uma condição invisível, que gera o isolamento social do homem.

São discriminados aqueles que não possuem acesso, ao menos, a um posto de trabalho. Por se encontrarem desempregados, sem uma renda que garanta o seu sustento e de sua família, não se incluem nos padrões predeterminados de vida social, sendo excluídos da "sociedade de consumo". Para essa parcela da sociedade, na qual estão incluídos muitos idosos, 
a saída do mercado de trabalho por meio da aposentadoria compulsória e a não previsão de reingresso na esfera produtiva, representam a desvalorização e o fracasso. Para a sociedade, a culpa pelo insucesso na inserção e permanência no mercado de trabalho está centrada única e exclusivamente na capacidade e esforço do trabalhador, não no sistema.

Vive-se num tempo em que o que importa é produzir. O desemprego é um fenômeno que marca o fim da utilidade da pessoa no âmbito social. Aqueles que produzem estão incluídos na sociedade, embora continuem participando do processo de exploração do trabalho pelo capital. Já aqueles que estão à margem do sistema, excluídos do processo, vivem de outros meios como o emprego informal e o subemprego, sem usufruírem dos direitos sociais garantidos em legislação.

$\mathrm{Na}$ realidade brasileira, as políticas sociais ainda são, em sua maioria, restritivas e compensatórias. Paralelamente à escassez de recursos, aumentam as demandas a que são destinados esses benefícios, ou seja, há mais pessoas que necessitam, que recursos disponíveis para atendê-las. Por outro lado, não há a intersetorialidade das políticas sociais públicas para o atendimento das necessidades básicas de todos aqueles que delas necessitam, fator este que agrava notavelmente as condições de vida das pessoas. O cumprimento dessa função estatal exige investimentos financeiros capazes de garantir acesso à saúde, habitação, alimentação, educação, assistência e aos demais direitos que estão constantemente se ampliando e se tornando mais complexos.
Atualmente, há toda uma mobilização da sociedade civil, dos grupos voluntários, dos movimentos populares e das associações profissionais que se organizam de forma a tentar suprir as lacunas deixadas pelo Estado em todas as esferas da sociedade. De acordo com Wolkmer, "na medida em que se amplia politicamente a pluralidade de esferas sociais, o espaço político unificado e homogêneo das formas de representação tradicional cede lugar a uma proliferação de práticas coletivas" (1994, p. 228).

Considera-se relevante a atuação organizada dos sujeitos para o enfrentamento das desigualdades sociais, todavia, a proliferação dessas iniciativas não pode eximir o Estado de suas responsabilidades para com os cidadãos. As demandas da população devem ser atendidas através de políticas públicas adequadas e eficientes, assegurando-se toda a garantia dos direitos sociais formalmente prescritos.

\section{As políticas sociais para essa faixa etá- ria da população}

Ao adentrar na velhice, o homem se depara com outra realidade socioeconômica diferente da época de vida produtiva, onde, através do exercício profissional cumpriu as horas a serem trabalhadas, as horas de descanso, as férias, e, depois de ter completado os anos de trabalho previstos em lei, depara-se com a aposentadoria (DUMAZEDIER, 1979).

Porém, é preciso pensar na realidade daqueles que vivem em países em via de desenvolvimento, como o Brasil, onde a maioria dos idosos não possui renda mensal satisfatória e, por isso, não desfru- 
tam de uma velhice plena, tendo que receber auxílio por meio de programas assistenciais. No cotidiano da realidade brasileira, ainda que se apresentem as mais variadas situações de vulnerabilidades, riscos e vitimizações entre a população, romper com essas circunstâncias é tarefa árdua, pois mesmo que a Constituição Federal (BRASIL, 1988) tenha instaurado a luta por valores como autonomia, cidadania e participação dos sujeitos, ainda hoje, não se admite a extensão do direito a todos os cidadãos.

$\mathrm{Na}$ atualidade, conquistas como o pleno emprego e a proteção social vêm sendo fragmentadas, perdas essas, que, numa sociedade denominada salarial, vem repercutir nos sujeitos, que acabam por serem discriminados por não conseguirem um posto de trabalho, sem se levar em conta as causas estruturais que gestam essa situação. Castel (1997) ressalta que, na medida em que se estreitam as condições para a efetivação do trabalho estáveis das gratificações e demais direitos trabalhistas, desagregam-se também os sistemas das proteções que foram progressivamente ligadas ao trabalho, retomando a vulnerabilidade de massas e, consequentemente, da exclusão.

Destaca ainda, que hoje não há mais apenas a figura do mendigo que por muito tempo dissimulou a existência de uma vulnerabilidade de massa na sociedade do antigo regime, mas há o que se pode qualificar de "sobrantes", que são os ex-trabalhadores assalariados que vivem hoje, uma precariedade permanente e a uma insegurança cotidiana pela ausência de um mercado organizado de trabalho. Na visão do mesmo autor, essas novas legiões de "sobrantes" tornaram-se o alvo central das políticas sociais, pois devido ao desemprego de longa duração, um contingente cada vez maior da população recorre às políticas públicas, independente que os sujeitos sejam crianças, adolescentes, jovens ou idosos.

Diante desta realidade, os idosos brasileiros vêm assumindo um papel relevante, uma vez que, por circunstâncias como o aumento do desemprego, muitos idosos são levados a agregarem em torno de si, filhos e netos. Schnorr (1998) ressalta que "a incapacidade dos jovens em gerir o próprio sustento dá origem a novas configurações familiares no contexto atual, pois é comum encontrar pessoas de diferentes gerações residindo juntas, compondo assim, novos "arranjos familiares", que são desencadeados mais por fatores econômicos que culturais."

Nesse contexto, os proventos advindos da aposentadoria ou pensão representam o sustento de toda a família. Com isso, a aposentadoria, que em outros países significa um período de merecido descanso, no Brasil torna-se um projeto relegado a um segundo plano. Embora não possuindo renda mensal satisfatória, o idoso em muitos casos torna-se o provedor indispensável do núcleo familiar.

Atualmente, a população de idosos representa um contingente de quase $15 \mathrm{mi}$ lhões de pessoas com 60 anos ou mais (8,6\% da população brasileira). Os dados do Instituto Brasileiro de Geografia e Estatística (IBGE) por meio da Pesquisa 
"Perfil dos Idosos Responsáveis pelos Domicílios no Brasil", (2012) revelam que o idoso brasileiro está cada vez mais cumprindo o papel de responsável pelo lar. A maioria destes chefes de família da terceira idade é do sexo masculino $(62,4 \%)$, tem idade média em torno de 69,4 anos e vivem sob o mesmo teto com esposa/companheira, filhos, enteados maiores de idade e netos. E em 50\% dos casos, estes filhos ou enteados têm 18 anos ou mais.

O Instituto Brasileiro de Geografia e Estatística (IBGE) chama a atenção para a grande proporção de domicílios unipessoais ocupados por mulheres idosas, fenômeno registrado tanto em 2000 como em 1991, as quais "Seriam mulheres viúvas, que não se casaram de novo". “(...) Como os viúvos ou separados se recasam com maior frequência que as mulheres nas mesmas condições, crescem significativamente a diferenciação dos arranjos familiares ou domiciliares em função do gênero e da idade do responsável", diz o texto do IBGE. Os mesmos dados mostram que as aposentadorias e pensões, pagas pela Previdência Social no Brasil, atendem não só às necessidades básicas dos idosos, mas de toda a família, que se torna sua dependente econômica direta, considerando-se ainda que a maioria receba benefícios de um salário mínimo. Conforme define o estudo, "nesses casos, os idosos são fatores de equilíbrio social e, não, ônus".

\section{Considerações finais}

Frente a um contingente da população cada vez mais amplo que envelhece, evi- dencia-se a necessidade de se procurar com urgência a formulação de políticas sociais, adequadas à população idosa em expansão e às futuras gerações. $O$ ser humano, nas diferentes etapas cronológicas da vida é um ser social que busca satisfazer suas necessidades através da relação com o meio onde se insere. Critérios como a falta de oportunidade de trabalho, disparidade de renda e o não cumprimento dos direitos humanos básicos para uma sobrevivência digna tornam-se realidade crescente no país. Sposati (2004) acredita que se faz necessário romper com a lógica perversa que assistência social é política para pobre, pois, só assim, ultrapassaremos a perspectiva conservadora de ajuda e caridade que acompanham o avanço da assistência social.

Nesse cenário, questões que envolvem a realidade do idoso vêm adquirindo crescente significado, tornando-se cada vez mais discutidas por diversos setores da sociedade contemporânea. Os debates em torno do Estatuto do Idoso (BRASIL, 2003) deram maior visibilidade a essa questão no plano político, econômico e social. Considerando-se o acelerado envelhecimento populacional, a situação da velhice segregada à margem da sociedade precisa ser revertida através de políticas públicas, que permitam condições de vida e saúde dignas para os idosos continuarem dando sua contribuição à sociedade, mantendo assim sua participação ativa na vida social.

Enquanto profissionais, temos que pensar a política de assistência social para além do campo da benesse, ou seja, é imprescindível continuarmos fazendo o exercí- 
cio para reafirmá-la no campo do direito e da dignidade humana. É preciso trabalhar em prol da definitiva ruptura do caráter clientelista que esteve presente ao longo de sua trajetória. Temos um projeto ético-político que se contrapõe às práticas paternalistas e às ideias neoliberais que estão postas na sociedade: conscientizar o usuário a acessar direitos é assumir, enquanto assistentes sociais, o empenho em fortalecer a população como cidadãos e não meramente como sujeitos beneficiários e subalternizados pela assistência.

\section{Referências}

\section{BRASIL. Constituição da República}

Federativa do Brasil. Brasília: Senado Federal, 1988.

BRASIL. Lei nº. 8.842, de 4 de Janeiro de 1994. Dispõe sobre a Política Nacional do Idoso, cria o Conselho Nacional do Idoso e dá outras providências. Disponível em: $<$ http://www.planalto.gov.br/ccivil_03/leis /18842.htm>.

DUMAZEDIER, Joffre. Sociologia empírica do lazer. São Paulo; Perspectiva, 1979.

ESTATÍSTICA, Instituto Brasileiro de Geografia/IBGE. Censos Demográficos dos anos de 1991 e 2000. Disponível em: <http://www.ibge.gov.br>.

ESTATÍSTICA, Instituto Brasileiro de Geografia/IBGE. Pesquisa Nacional de Amostra por Domicílio (PNAD) Brasil. Brasília, 2012. Disponível em: http://www.ibge.gov.br.
ESTATÍSTICA, Instituto Brasileiro de Geografia/IBGE. Perfil dos idosos responsáveis pelos domicílios no Brasil. Brasília, 2012. Disponível em: $<$ http://www.ibge.gov.br>.

KUNZLER, Rosilaine Brasil. A Ressignificação da vida cotidiana a partir da aposentadoria e do Envelhecimento. 2009. Tese (Doutorado) - Faculdade de Serviço Social, Programa de Pós-Graduação em Serviço Social, Pontifícia Universidade Católica do Rio Grande do Sul, Porto Alegre, 2009.

SCHNORR, Ruthe Corrêa da Costa. O cotidiano de trabalho na Terceira Idade: uma realidade em questão. 1998.

Dissertação (Mestrado) - Faculdade de Serviço Social, Programa de PósGraduação em Serviço Social, Pontifícia Universidade Católica do Rio Grande do Sul, Porto Alegre, 1998.

SPOSATI, Aldaíza de Oliveira (Org.). Proteção social de cidadania: inclusão de idosos e pessoas com deficiência no Brasil, França e Portugal. São Paulo: Cortez, 2004.

WOLKMER, Antonio Carlos. Pluralismo jurídico: fundamentos de uma nova cultura no direito. São Paulo: AlfaÔmega, 1994 